\title{
1,2,3-Triazoles from carbonyl azides and alkynes: filling the gap $\dagger$
}

Cite this: Chem. Commun., 2014, 50, 8978

Received 13th May 2014,

Accepted 17th June 2014

DOI: $10.1039 / c 4 c c 03614 j$

www.rsc.org/chemcomm

\author{
Estela Haldón, ${ }^{a}$ Eleuterio Álvarez, ${ }^{b}$ M. Carmen Nicasio*c and Pedro J. Pérez ${ }^{\star^{a}}$
}

\begin{abstract}
Electron deficient azides are challenging substrates in CuAAC reactions. Particularly, when $\mathrm{N}$-carbonyl azides are applied the formation of $\mathrm{N}$-carbonyl triazoles has not yet been observed. We report herein the first example of this class of reaction, with a copper-based system that efficiently enables the synthesis of $N$-carbamoyl 1,2,3-triazoles by [3+2] cycloaddition of $\mathrm{N}$-carbamoyl azides and alkynes.
\end{abstract}

Despite the 1,2,3-triazole ring does not occur in nature, synthetic molecules that contain this heterocyclic unit show diverse biological activities. ${ }^{1}$ The Huisgen thermal 1,3-dipolar cycloaddition reaction ${ }^{2}$ of alkynes and organic azides is the most straightforward route for the synthesis of this interesting and notable stable five-membered heterocycle. However, the selectivity of the process is low, yielding mixtures of 1,4- and 1,5-disubstituted regioisomers. A major development in the field was made, independently, in 2002 by the groups of Meldal $^{3}$ and Sharpless: ${ }^{4}$ the copper-catalyzed version of the Huisgen reaction, which remarkably improved the reaction rate and the selectivity, since it provided exclusively 1,4-disubstituted 1,2,3-triazoles in very high yields, overcoming the drawbacks of the original Huisgen procedure. Since then, the copper-catalyzed azidealkyne cycloaddition (CuAAC) ${ }^{5}$ (Scheme 1a) has found tremendous applications in several disciplines ${ }^{5-8}$ due to its versatility, in terms of both reaction conditions and functional group compatibility.

However, electron deficient azides are challenging substrates since they do not very frequently provide the corresponding 1,2,3-triazoles. Thus, $N$-sulfonyl or $N$-phosphoryl azides usually

\footnotetext{
${ }^{a}$ Laboratorio de Catálisis Homogénea, Unidad Asociada al CSIC, CIQSO-Centro de Investigación en Quimica Sostenible and Departamento de Quimica y Ciencias de los Materiales, Campus de El Carmen s/n, Universidad de Huelva, 21007-Huelva, Spain.E-mail:perez@dqcm.uhu.es

${ }^{b}$ Instituto de Investigaciones Quimicas Isla de la Cartuja, CSIC-Universidad de Sevilla, Avenida de Américo Vespucio 49, 41092-Sevilla, Spain

${ }^{c}$ Departamento de Química Inorgánica, Universidad de Sevilla, Aptdo 1203, 41071-Sevilla, Spain.E-mail: mnicasio@us.es

$\dagger$ Electronic supplementary information (ESI) available: Detailed experimental procedures, analytical and spectroscopic data, and X-ray crystallographic data. CCDC 1002750 (1), 1002751 (4), 1002752 (5) and 1002753 (8). For ESI and crystallographic data in CIF or other electronic format see DOI: 10.1039/ c4cc03614j
}

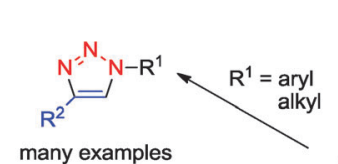

(a)

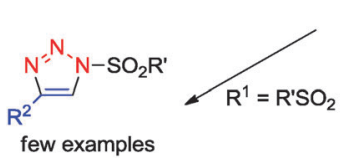

(b)

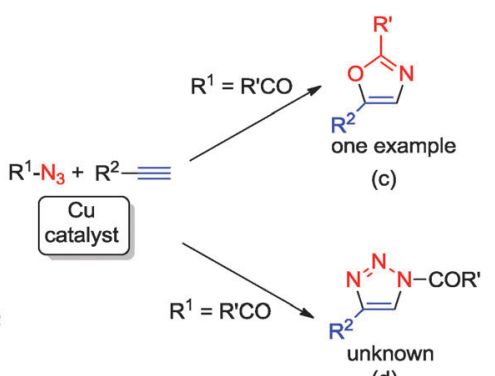

(d)
Scheme 1 Synthesis of 1,2,3-triazoles and oxazoles via CuAAC.

react with alkynes, in the presence of the corresponding catalyst, rendering products derived from the reaction of ketenimine species, formed upon ring-opening of the triazole-cuprate intermediates, with nucleophiles. ${ }^{9}$ Scarcely, a few systems have been described in which the presence of certain ligands ${ }^{10 a}$ or the use of copper(I) complexes ${ }^{10 b, c}$ allowed the formation of the 1,2,3-triazoles, particularly when $N$-sulfonyl azides are applied (Scheme 1b). ${ }^{10}$ A few years ago, we found that the complex $\left[\mathrm{Tpm}^{*}, \mathrm{Br} \mathrm{Cu}(\mathrm{NCMe})\right] \mathrm{BF}_{4} \quad\left(\mathrm{Tpm}^{*}{ }^{* \mathrm{Br}}=\operatorname{tris}(3,5\right.$-dimethyl-4-bromopyrazolyl)methane) also promoted the exclusive formation of $N$-sulfonyl-1,2,3-triazoles in the cycloaddition reaction of $N$-sulfonyl azides with terminal alkynes. ${ }^{11}$ Shortly after we found that when $\mathrm{N}$-carbonyl azides were applied under the same catalytic conditions, 1,5-disubstituted oxazoles were isolated as products ${ }^{12 a}$ (Scheme 1c) instead of the expected 1,2,3- $N$-carbonyl triazoles. To date, and to the best of our knowledge, the direct formation of $\mathrm{N}$-carbonyl1,2,3-triazoles by CuAAC using $N$-carbonyl azides as substrates (Scheme 1d) remains undescribed. Herein, we report the synthesis of 1,4-disubstituted $N$-carbamoyl 1,2,3-triazoles from the cycloaddition reaction of $N$-carbamoyl azides and alkynes catalyzed by $\left[\mathrm{Tpa}^{*} \mathrm{Cu}\right] \mathrm{PF}_{6},\left(\mathrm{Tpa}^{*}=\right.$ tris(3,5-dimethyl-pyrazolylmethyl)amine), which can be considered the first example of the formation of $N$-carbonyl 1,2,3,-triazole derivatives from a CuAAC reaction of a $N$-carbonyl azide. It is worth mentioning that the products prepared by this methodology have been described to be potent inhibitors of serine hydrolases. ${ }^{13}$ 


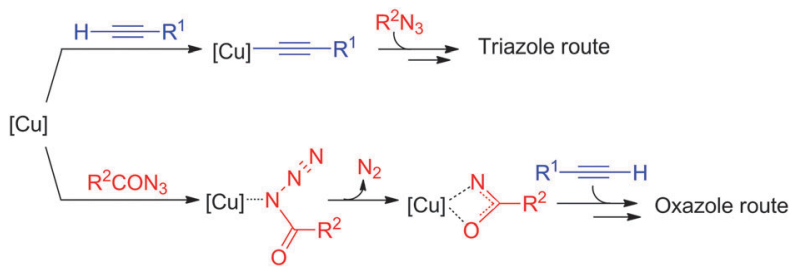

Scheme 2 Reaction intermediates for the formation of triazoles and oxazoles through CuAAC.

As mentioned above, we encountered a different reactivity for $N$-carbonyl azides in the CuAAC that led to the isolation of 1,5-disubstituted oxazole derivatives. Mechanistic studies showed ${ }^{12 b}$ that the reaction proceeded not through the copper-acetylide intermediate usually invoked to trigger the formation of a triazolylcuprate intermediate, but with the intermediacy of copper-nitrene species formed from the azide reactant (Scheme 2). Therefore, this distinct behaviour seems to govern the reaction outcome: triazoles required a copper-acetylide species whereas oxazoles formed from a copper nitrene intermediate. With this idea in mind, we thought about the electronic characteristics that $N$-carbonyl azide would require to disfavour the formation of the latter. We turned our attention to $\mathrm{N}$-carbamoyl azides, a class of carbonyl azides that require gentle heating to promote $\mathrm{N}_{2}$ extrusion. ${ }^{14}$ This feature, along with the delocalization of electronic density along the $\mathrm{N}-\mathrm{C}(\mathrm{O})-\mathrm{N}$ moiety due to conjugation, ${ }^{15}$ could disfavour the extrusion of dinitrogen and concomitant formation of the copper-nitrene intermediate, with the subsequent appearance of copper-acetylides as more probable intermediates.

With the above idea in mind, we examined the potential of complex $\left[\mathrm{Tpa}^{*} \mathrm{Cu}\right] \mathrm{PF}_{6}$ as the catalyst precursor in the reaction of $N$-morpholinocarbamoyl azide and phenyl acetylene (Scheme 3). This complex has been found to promote the formation of oxazoles from $N$-carbonyl azides and alkynes. ${ }^{12 b}$ Pleasingly, the reaction proceeded with the isolation of a product whose spectroscopic features did not resemble those of an oxazole but those of a triazole derivative. For instance, a distinct sharp singlet resonance was observed in the high frequency region of its ${ }^{1} \mathrm{H}$ NMR spectrum at $\delta 8.37$ and a strong absorption $\left(c a .1686 \mathrm{~cm}^{-1}\right)$ was also found in the typical carbonyl region of its IR spectrum (see ESI $\dagger$ for more details). The presence of the 1,2,3-triazole structure was confirmed from an X-ray analysis (Scheme 3). Isolated yield was $70 \%$.

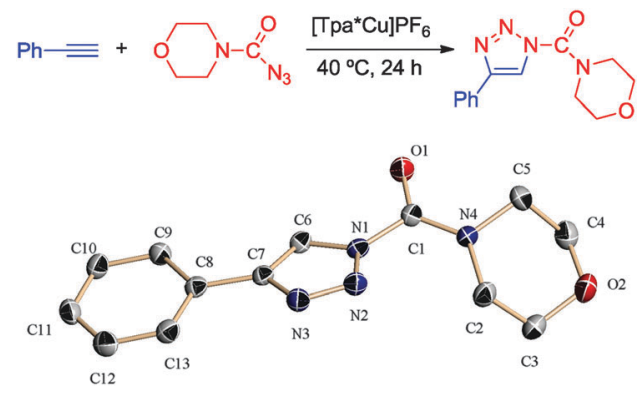

Scheme 3 Reaction of $\mathrm{N}$-morpholinocarbamoyl azide and phenyl acetylene catalyzed by $\left[\mathrm{Tpa}^{\star}{ }_{\mathrm{Cu}} \mathrm{PF}_{6}\right.$.
Table 1 Optimization of the reaction conditions ${ }^{a}$

\begin{tabular}{|c|c|c|c|}
\hline Entry & Catalyst & Solvent & Yield $^{b}$ \\
\hline 1 & {$\left[\mathrm{Tpa}^{*} \mathrm{Cu}\right] \mathrm{PF}_{6}$} & DCE & 70 \\
\hline 2 & {$\left[\mathrm{Tpm}^{*}, \mathrm{Br} \mathrm{Cu}(\mathrm{CNMe})\right] \mathrm{BF}_{4}$} & DCE & - \\
\hline 3 & {$\left[\mathrm{Tpm}^{*}, \mathrm{Br} \mathrm{Cu}(\mathrm{CNMe})\right] \mathrm{BF}_{4}$} & $\mathrm{CHCl}_{3}$ & - \\
\hline 4 & {$[\mathrm{TpaCu}] \mathrm{PF}_{6}{ }^{c}$} & DCE & - \\
\hline 5 & {$\left[\mathrm{Tpa}{ }^{*}, \mathrm{Br}^{\vec{C}} \mathrm{Cu}\right] \mathrm{PF}_{6}{ }^{d}$} & DCE & 50 \\
\hline 6 & {$\left[\mathrm{Tpa}{ }^{*} \mathrm{Cu}\right] \mathrm{PF}_{6}$} & None & 70 \\
\hline 7 & {$\left[\mathrm{Tpa}^{*} \mathrm{Cu}\right] \mathrm{PF}_{6}$} & DCE & $65^{e}$ \\
\hline 8 & {$\left[\mathrm{Tpa}^{*} \mathrm{Cu}\right] \mathrm{PF}_{6}$} & DCE & $70^{f}$ \\
\hline 9 & None & DCE & - \\
\hline
\end{tabular}

${ }^{a}$ Reactions conditions: phenyl acetylene $(1.2 \mathrm{mmol}), \mathrm{N}$-morpholino carbamoyl azide $(1 \mathrm{mmol})$, catalyst $(5 \mathrm{~mol} \%)$, solvent $(1 \mathrm{~mL}) .{ }^{b}$ Isolated yields. ${ }^{c}$ Tpa $=$ tris(pyrazolylmethyl)amine. ${ }^{d} \mathrm{Tpa}^{*, \mathrm{Br}}=\operatorname{tris}(3,5$-dimethyl4-bromo-pyrazolylmethyl)amine. ${ }^{e} 10 \mathrm{~mol} \%\left[\mathrm{Tpa}^{*} \mathrm{Cu}\right] \mathrm{PF}_{6} \cdot{ }^{f}$ Phenyl acetylene $(1 \mathrm{mmol}), \mathrm{N}$-morpholino carbamoyl azide $(2.5 \mathrm{mmol})$.

We tested other catalyst precursors but neither of them resulted to be active in this transformation (Table 1, entries 1-5). Having identified the most promising catalyst precursor, other parameters were examined. The use of the neat conditions, the increase of the catalyst loading and the modification of the phenyl acetylene/ $N$-morpholinocarbamoyl azide ratio did not produce any significant effect on the yield (entries 6-8). It is worth mentioning that the control experiment carried out without the copper complex resulted in no product formation (entry 9). Finally, the reaction did not proceed when the organic azide was generated in situ from the corresponding organic halide.

The scope of this transformation with regard to the alkyne reactant is shown in Scheme 4. The reactions proceeded smoothly at $40{ }^{\circ} \mathrm{C}$ with different aryl-substituted acetylenes affording 1,4-disubstituted 1,2,3-N-carbamoyl triazoles in good yields (1-4).

The outcome was largely unaffected by the electronic nature of the substituents on the aromatic ring of the alkyne.

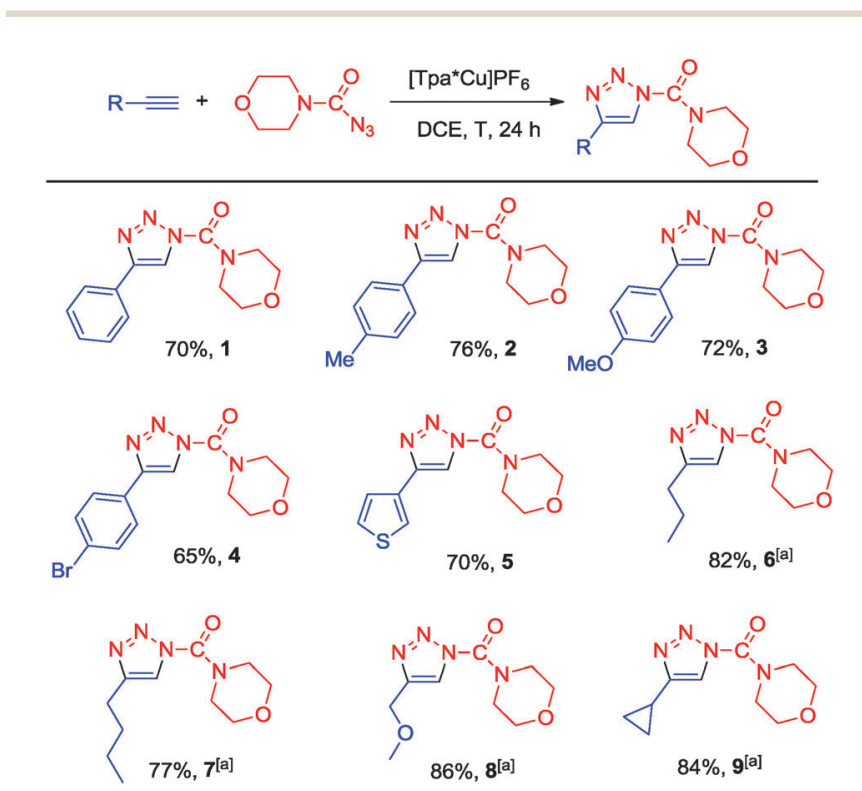

Scheme 4 [3+2] Cycloaddition of $N$-morpholinocarbamoyl azide with 1 -alkynes catalyzed by $\left[\mathrm{Tpa}^{*} \mathrm{Cu}_{\mathrm{P}} \mathrm{PF}_{6}\right.$. Reaction conditions: azide $(1 \mathrm{mmol})$, alkyne $(1.2 \mathrm{mmol}), \mathrm{DCE}(1 \mathrm{~mL}), 40{ }^{\circ} \mathrm{C}, 24 \mathrm{~h}$. Isolated yields based on azide (average of two runs). ${ }^{a}$ The reaction was performed at $60{ }^{\circ} \mathrm{C}$. 

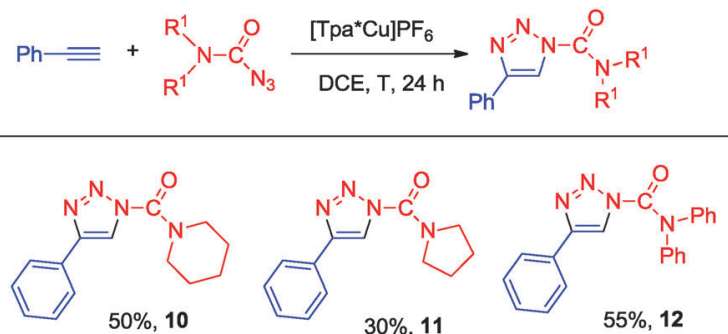

Scheme 5 [3+2] Cycloaddition of $\mathrm{N}$-carbamoyl azide with phenyl acetylene catalyzed by $\left[\mathrm{Tpa}^{*} \mathrm{Cu}\right] \mathrm{PF}_{6}$. Reaction conditions: azide ( $\left.1 \mathrm{mmol}\right)$, alkyne $(1.2 \mathrm{mmol}), \mathrm{DCE}(1 \mathrm{~mL}), 40{ }^{\circ} \mathrm{C}, 24 \mathrm{~h}$. Isolated yields based on azide (average of two runs).

Moreover, the process was compatible with the presence of a sulphur-containing heterocycle on the alkyne (5). Alkylsubstituted acetylenes were also tested as substrates, but the reactions had to be carried out at higher temperatures $\left(60^{\circ} \mathrm{C}\right)$ to reach good conversions. Once more, the products were obtained in high yields regarding the nature of the alkyl group (6-9). As commonly observed in CuAAC reactions, internal alkynes were totally inert under these conditions. ${ }^{16}$

To further explore the scope of the reaction, different $N$-carbamoyl azide substrates were subjected to this $[3+2]$ cycloaddition reaction with phenyl acetylene (Scheme 5). In all cases, the corresponding $N$-carbamoyl 1,2,3-triazoles were formed under the reaction conditions, although yields were lower than that found for the model substrate.

$\mathrm{N}$-Carbamoyl triazoles have proven to be potent serine hydrolase inhibitors. ${ }^{13}$ The reported method for the synthesis of these compounds consists of a two step procedure which involves the preparation of $1 \mathrm{H}$-1,2,3-triazole via CuAAC and its subsequent coupling with a $\mathrm{N}$-aminecarbonyl chloride. Mixtures of N1- and N2-carbamoylated regioisomers are obtained. Instead, with our synthetic approach only the N1-regioisomer is achieved in good yields in a one-step catalytic procedure. ${ }^{13 a}$ In addition, the precatalyst $\left[\mathrm{Tpa}^{*} \mathrm{Cu}\right] \mathrm{PF}_{6}$ is easy to make ${ }^{17}$ and sufficiently stable to moisture and air to be weighted on a benchtop.

Scheme 6 displays a general mechanistic explanation for the reaction of several azides and alkynes in the presence of this type of copper catalysts. Two possible pathways can be invoked to explain the formation of 1,2,3-triazoles from $N$-sulfonyl- or $\mathrm{N}$-carbamoyl azides or that of oxazoles from $\mathrm{N}$-carbonyl azides. In the latter, the metal centre prefers the azide group to form a nitrene intermediate, which reacts further with the alkyne ${ }^{12 b}$ rendering the formation of the oxazole (Scheme 6, cycle A). On the other hand, the $\mathrm{N}$-sulfonyl- or $\mathrm{N}$-carbamoyl azides do not lead to nitrene intermediates, since the formation of copper acetylides must be favored. From here, interaction with the azide and subsequent formation of the triazolyl-cuprate could explain the formation of the triazole derivatives (Scheme 6, cycle B). The intermediacy of two copper centres for the $[3+2]$ reaction to occur has been previously proposed by several groups. ${ }^{18}$ In our case, we cannot rule out the assistance of a second molecule of the catalyst in the process.

In summary, we have discovered a $\mathrm{Cu}(\mathrm{I})$ precursor that for the first time allows the formation of $\mathrm{N}$-carbonyl triazoles by

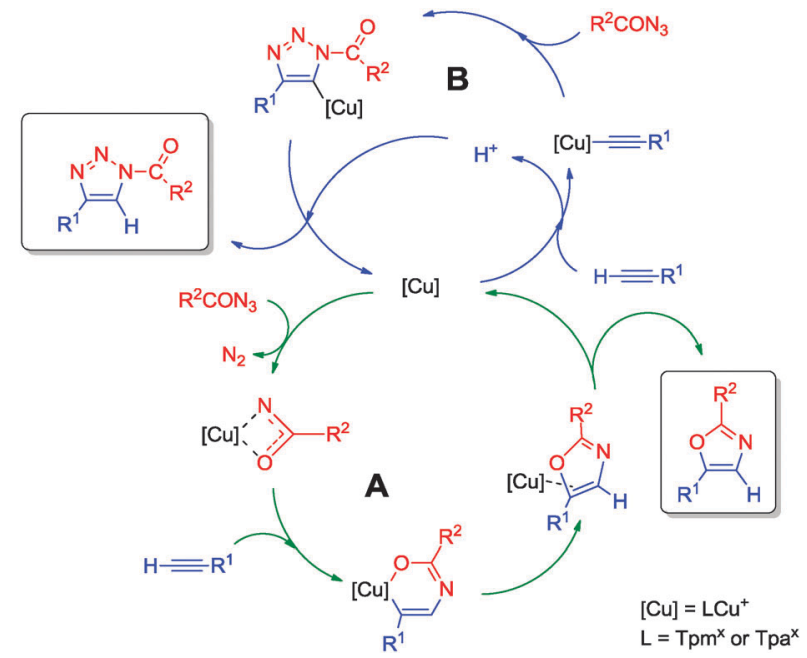

Scheme 6 Mechanistic proposal for the formation of oxazoles (a) and triazoles (b) through the reaction of carbonyl azides and terminal alkynes catalyzed by $\left[\mathrm{Tpa}{ }^{\star} \mathrm{Cu}_{\mathrm{PF}}\right.$.

CuAAC reaction with $N$-carbamoyl azides as substrates. This mild protocol represents a powerful alternative to existing procedures for the preparation of this class of bioactive compounds from readily available starting material. Further investigations to extend the scope of this transformation are ongoing in our laboratory.

We thank MINECO (CTQ2011-28942-CO2-01, CTQ2011-27033) and Junta de Andalucía (Proyecto P07-FQM-02745, P10-FQM-06292). EH thanks MEC for a research grant.

\section{Notes and references}

1 (a) L. L. Brockunier, E. R. Parmee, H. O. Ok, M. R. Candelore, M. A. Cascieri, L. F. Colwell Jr., L. Deng, G. J. Hom, W. P. Feeney, M. J. Forrest, G. J. Hom, D. E. MacIntyre, L. Tota, M. J. Wyvratt, M. H. Fisher and A. E. Weber, Bioorg. Med. Chem. Lett., 2000, 10, 2111; (b) B. S. Holla, M. Mahalinga, M. S. Karthikeyan, B. Poojary, P. M. Akberali and N. S. Kumari, Eur. J. Med. Chem., 2005, 40, 1173; (c) V. Pande and J. M. Ramos, Bioorg. Med. Chem. Lett., 2005, 15, 5129; (d) M. Whitting, J. Muldoon, Y.-C. Lin, S. M. Silverman, W. Lindstrom, A. J. Olson, H. C. Kolb, M. G. Finn, K. B. Sharpless, J. H. Elder and V. V. Fokin, Angew. Chem., Int. Ed., 2006, 45, 1435; (e) M. Aufort, J. Herscovici, P. Bouhours, N. Moreau and C. Girard, Bioorg. Med. Chem. Lett., 2008, 18, 1195; (f) S. R. Patpi, L. Pulipati, P. Yogeeswari, D. Sriram, N. Jain, B. Sridhar, R. Murthy, T. A. Devi, S. V. Kalivendi and S. Kantevari, J. Med. Chem., 2012, 55, 3911.

2 (a) R. Huisgen, Angew. Chem., Int. Ed. Engl., 1963, 2, 565; (b) R. Huisgen, Angew. Chem., Int. Ed. Engl., 1963, 2, 633; (c) R. Huisgen, Pure Appl. Chem., 1989, 61, 613.

3 C. W. Tornøe, C. Christensen and M. P. Meldal, J. Org. Chem., 2002, 67, 3057.

4 V. V. Rostovtsev, L. G. Green, V. V. Fokin and K. B. Sharpless, Angew. Chem., Int. Ed., 2002, 41, 2596.

5 For general reviews on CuAAC reactions, see: (a) V. D. Bock, H. Hiemstra and J. H. van Maarseveen, Eur. J. Org. Chem., 2006, 51; (b) J. E. Moses and A. D. Moorhouse, Chem. Soc. Rev., 2007, 36, 1249; (c) M. P. Meldal and C. W. Tornøe, Chem. Rev., 2008, 108, 2952; (d) J. E. Hein and V. V. Fokin, Chem. Soc. Rev., 2010, 39, 1302; (e) S. Díez-González, Catal. Sci. Technol., 2011, 1, 166.

6 For applications in drug discovery see for example: $(a)$ H. C. Kolb and K. B. Sharpless, Drug Discovery Today, 2003, 8, 1128; (b) J.-F. Lutz and Z. Zarafshani, Adv. Drug Delivery Rev., 2008, 60, 958; (c) G. C. Tron, T. Pirali, R. A. Billington, P. L. Caninico, G. Sorba and A. A. Genazzani, Med. Res. Rev., 2008, 28, 278; (d) A. D. Moorhouse 
and J. E. Moses, ChemMedChem, 2008, 3, 715; (e) S. G. Agalave, S. R. Maujan and V. S. Pore, Chem. - Asian J., 2011, 6, 2696; $(f)$ E. Lallana, A. Sousa-Herves, F. Fernandez-Trillo, R. Riguera and E. Fernandez-Megia, Pharm. Res., 2012, 29, 1; $(g)$ P. Thirumurugan, D. Matosiuk and K. Jozwiak, Chem. Rev., 2013, 113, 4905.

7 For applications in biochemistry see for example: (a) J. M. Baskin and C. R. Bertozzi, QSAR Comb. Sci., 2007, 26, 1211; (b) V. Hong, S. I. Presolski, C. Ma and M. G. Finn, Angew. Chem., Int. Ed., 2009, 48, 9879; (c) S. K. Mamidyala and M. G. Finn, Chem. Soc. Rev., 2010, 39, 1252; (d) A. H. El-Sagheer and T. Brown, Chem. Soc. Rev., 2010, 39, 1388; (e) C. Besanceny-Webler, H. Jiang, T. Zheng, L. Feng, D. Soriano del Amo, W. Wang, L. M. Klivansky, F. L. Marlow, Y. Liu and P. Wu, Angew. Chem., Int. Ed., 2011, 50, 8051.

8 For applications in material science see for example: (a) J.-F. Lutz, Angew. Chem., Int. Ed., 2007, 46, 1018; (b) W. H. Binder and R. Sachenhofer, Macromol. Rapid Commun., 2007, 28, 15; (c) M. P. Meldal, Macromol. Rapid Commun., 2008, 29, 1016; (d) L. Liang and D. Astruc, Coord. Chem. Rev., 2011, 255, 2933.

9 (a) I. Bae, H. Han and S. Chang, J. Am. Chem. Soc., 2005, 127, 2038; (b) S. H. Cho, E. J. Yoo, I. Bae and S. Chang, J. Am. Chem. Soc., 2005, 127, 16046; (c) M. Whiting and V. V. Fokin, Angew. Chem., Int. Ed., 2006, 45, 3157; (d) E. J. Yoo, M. Ahlquist, I. Bae, K. B. Sharpless, V. V. Fokin and S. Chang, J. Org. Chem., 2008, 73, 5520; (e) S. H. Kim, S. H. Park, J. H. Choi and S. Chang, Chem. - Asian J., 2011, 6, 2618 and references therein.

10 (a) E. J. Yoo, M. Ahlquist, S. H. Kim, I. Bae, V. V. Fokin, K. B. Sharpless and S. Chang, Angew. Chem., Int. Ed., 2007, 46, 1730; (b) F. Wang, H. Fu, Y. Jiang and Y. Zhao, Adv. Synth. Catal., 2008, 350, 1830; (c) J. Raushel and V. V. Fokin, Org. Lett., 2010, 12, 4952. 11 I. Cano, M. C. Nicasio and P. J. Pérez, Org. Biomol. Chem., 2010, 8, 536.
12 (a) I. Cano, E. Álvarez, M. C. Nicasio and P. J. Pérez, J. Am. Chem. Soc., 2011, 133, 191; (b) E. Haldón, M. Besora, I. Cano, X. C. Cambeiro, M. A. Pericás, F. Maseras, M. C. Nicasio and P. J. Pérez, Chem. - Eur. J., 2014, 20, 3463.

13 (a) A. Adibekian, B. R. Martin, C. Wang, K.-L. Hsu, D. A. Bachovchin, S. Niessen, H. Hoover and B. F. Cravatt, Nat. Chem. Biol., 2011, 7, 469; (b) K.-L. Hsu, K. Tsuboi, A. Adibekian, H. Pugh, K. Masuda and B. J. Cravatt, Nat. Chem. Biol., 2012, 8, 999; (c) K.-L. Hsu, K. Tsuboi, L. R. Whitby, A. E. Speers, H. Pugh, J. Inloes and B. J. Cravatt, J. Med. Chem., 2013, 56, 8257; (d) K.-L. Hsu, K. Tsuboi, J. W. Chang, L. R. Whitby, A. E. Speers, H. Pugh and B. F. Cravatt, J. Med. Chem., 2013, 56, 8270; (e) N. Aaltonen, J. R. Savinainen, C. Riera Ribas, J. Rönkkö, A. Kuusisto, J. Korhonen, D. Navia-Paldanius, J. Häyrinen, P. Takabe, H. Käsnänen, T. Pantsar, T. Laitinen, M. Lehtonen, S. Pasonen-Seppänen, A. Poso, T. Nevalainen and J. T. Laitinen, Chem. Biol., 2013, 20, 379.

14 W. Lwowski, in Azides and Nitrenes: Reactivity and Utility, ed. E. Scriven, Academic Press Inc., 1984, p. 206.

15 Y. Umar, Spectrochim. Acta, Part A, 2006, 64, 568.

16 Internal alkynes do not normally react under copper catalysis conditions but there are two examples reported: (a) S. González-Díez, A. Correa, L. Cavallo and S. P. Nolan, Chem. - Eur. J., 2006, 12, 7558; (b) N. Candelon, D. Lastécouères, A. K. Diallo, J. R. Aranzaes, D. Astruc and J.-M. Vincent, Chem. Commun., 2008, 741.

17 K. Fujisawa, S. Chiba, Y. Miyashita and K. Okamoto, Eur. J. Inorg. Chem., 2009, 3921.

18 (a) B. T. Worrell, J. A. Malik and V. V. Fokin, Science, 2013, 340, 457; (b) R. Berg and B. F. Straub, Beilstein J. Org. Chem., 2013, 9, 2715 and references therein. 